\title{
AS TEMERÁRIAS AVENTURAS DE UM TRADUTOR NÃO- NATIVO NOS JARDINS DA POESIA POLONESA
}

\author{
The Daredevil Adventures of a Non-Native Translator in the Gardens of \\ Polish Poetry
}

\author{
Vojislav Aleksandar JOVANOVIC \\ Universidade de São Paulo \\ jovanov@usp.br. \\ https://orcid.org/0000-0002-3054-6026
}

\begin{abstract}
RESUMO:A presente apresentação objetiva problematizar a questão da operação tradutória e, de modo particular, da tradução do gênero poético. De outro lado, tem como finalidade enquadrar a experiência do autor na tradução de poemas de alguns poetas poloneses, embora não tenha sido este o foco central ao longo de sua produção tradutória. Entendemos que se pode caracterizar a tradução como operação linguístico-cultural, uma vez que a transposição de conteúdos de uma língua de partida para uma de chegada representa ab ovo o diálogo entre culturas. Por óbvio, trata-se de definição simplificada de relação estabelecida entre dois sistemas de significação e dois grupos etnoculturais. A incursão pessoal na tradução de poesia polonesa para o português materializouse, sobretudo, na antologia intitulada Céu Vazio - 63 poetas eslavos (São Paulo: Hucitec,1996) em que foram traduzidos textos de poetas poloneses, sérvios, tchecos, eslovenos, croatas e macedônios. Todos os poetas inseridos no livro são escritores do século XX; a única exceção foi Jan Kochanowski, que aparece no livro com três poemas traduzidos.
\end{abstract} PALAVRAS-CHAVE: Literatura polonesa; Poesia; Tradução; Teoria da tradução.

\begin{abstract}
This presentation aims to discuss the question of translation operation and, in particular, of the translation of the poetic genre. On the other hand, its purpose is to frame the author's experience in the translation of poems by some Polish poets, although this was not the central focus throughout his translation production. We understand that translation can be characterized as a linguistic-cultural operation, since the transposition of contents from a source language into a target language represents an open dialogue between cultures. Obviously, it is a simplified definition of the relationship established between two systems of meaning and two ethnocultural groups. The personal foray into the translation of Polish poetry into Portuguese materialized, above all, in the anthology entitled Empty Sky (Céu Vazio)- 63 Slavic poets
\end{abstract}


(São Paulo: Hucitec, 1996) in which texts of Polish, Serbian, Czech, Slovenian, Croatian and Macedonians poets were translated. All the poets in the book are twentieth-century writers; The only exception was Jan Kochanowski, who appears in the book with three translated poems. KEY-WORDS: Polish literature; Poetry; Translation; Translation studies.

STRESZCZENIE: Niniejsza prezentacja ma na celu omówienie kwestii operacji tłumaczeniowej, a zwłaszcza tłumaczenia gatunku poetyckiego. $Z$ drugiej strony jej celem jest ujęcie doświadczenia autora w tłumaczeniu wierszy niektórych polskich poetów, chociaż nie było to głównym celem całej jego działalności przekładowej. Rozumiemy, że thumaczenie można opisać jako operację językowo-kulturową, ponieważ transpozycja treści z języka źródłowego na język docelowy pokazuje $a b$ ovo dialog między kulturami. Oczywiście jest to uproszczona definicja relacji ustanowionej między dwoma systemami znaczeń i dwiema grupami etniczno-kulturowymi.Osobista próba thumaczenia polskiej poezji na portugalski zmaterializowała się przede wszystkim w antologii zatytułowanej Puste niebo - 63 poetów słowiańskich (São Paulo: Hucitec, 1996), w której zostały przetłumaczone teksty poetów polskich, serbskich, czeskich, słoweńskich, chorwackich i macedońskich. Wszyscy poeci tłumaczeni w książce są pisarzami dwudziestowiecznymi; jedynym wyjątkiem jest Jan Kochanowski. W książce opublikowane są trzy jego wiersze w thumaczeniu. SŁOWA KLUCZOWE: Literatura polska; Poezja; Przekład; Teoria przekładu.

Tradução do resumo: Piotr Kilanowski

$\mathrm{O}$ ato tradutório é sempre um desafio múltiplo, porque depende do fazerinterpretativo de um enunciatário - nesse caso particular, o tradutor - que deve pôr à prova o seu saber-fazer-enunciativo situado num tempo, num espaço e também num sistema de significação diversos daquele em que o texto foi enunciado/produzido. Traduzir é sinônimo de uma operação interlinguística e, também, de uma operação intercultural, de modo que se pode afirmar que é certa forma de comunicação entre culturas.

Traduttore, traditore. O jogo paronomástico encerrado na conhecida expressão italiana sintetiza, de modo sutil, mas exato, os dilemas a que está exposta a tradução, complexa operação interlinguistica, interssemiótica e intercultural. Imaginar que se pode afirmar que a tradução consiste em transpor simplesmente determinado conteúdo de uma substância linguística (chamada de língua de partida) para outra substância linguística 
(chamada de língua de chegada) é uma abordagem simplista e ingênua. Há muito mais questões a serem levadas em consideração nesse processo de escolhas delicadas e de sucessivas (e inevitáveis) perdas e ganhos.

Que as línguas são, em primeiro lugar, uma espécie de fio condutor da visão de mundo de qualquer comunidade sociolinguística e cultural foi enunciado, ainda no século XIX, por Wilhelm von Humboldt (que a denominou de Weltanschauung, termo depois apropriado, de certo modo, pela Teoria da Literatura) e a tese hoje é aceita, sem reservas, pelas Ciências da Linguagem. Há quase três décadas, Haroldo de Campos, num texto que se tornou canônico (CAMPOS, 1987), chamava a tradução de operação tradutora, que não pode ser resumida à simples transposição termo-a-termo de um texto qualquer, de um idioma para outro.

Cabe destacar que, desde que começamos a trabalhar com tradução, adotamos, claramente e $a b$ initio, um princípio formulado por Haroldo de Campos, há décadas, num texto que já se tornou clássico: "Traduzir há de ser criar- re-criar, sob pena de esterilização, e petrificação, o que é pior que a alternativa de trair" (CAMPOS, 1976, p. 43). O tradutor deve restabelecer, re- criar na língua de chegada as relações contraídas entre os planos do conteúdo e da expressão no idioma de partida. Este problema agravase, dramatiza-se, quando se trata de um texto poético. As razões parecem óbvias, face à pluri-isotopia dos textos de natureza poética. Se atentarmos para os conceitos formulados por Haroldo de Campos a respeito da transcriação poética, veremos que subjaz a noção de paramorfismo a ser estabelecido entre original e texto traduzido, de tal modo que o ato tradutório resulta em criação autônoma, paralela, mas recíproca (CAMPOS, 1976).

Por outro lado, a formulação de Campos põe em xeque o par excludente fixado por Ewald Osers, ou seja, da fidelidade infiel e da infidelidade fiel (ПОПОВА, 1983) Em outras palavras: para Osers, a fidelidade infiel acaba sendo uma cópia formal da língua de partida na língua de chegada, sem levar em conta os diversos aspectos e níveis do texto - definição que endossamos -, ao passo que a infidelidade fiel está vinculada à ideia da transcriação de uma língua para a outra. Porém é preciso ter consciência aguda do fato de que toda e qualquer tradução resulta, em primeiro lugar, de uma leitura idiossincrática realizada pelo tradutor e, ainda, que tradução alguma é capaz de dar conta de todos os estratos de um texto. Não há relação biunívoca entre o texto na língua-fonte e o texto na língua-alvo. Há um contínuo devir entre ganhos e perdas durante o ato tradutório, ganhos e perdas que se cristalizam, em caráter definitivo, no produto desse ato, no texto traduzido.

A disjunção poesia/prosa deixa de ser relevante frente a esta noção de tradução como re-criação ou transcriação, uma vez que a condição sine qua non está vinculada 
ao critério das dificuldades apresentadas no texto da língua de partida. Devemos aduzir que essa tradução-transcriação deve ser entendida, também, como transcodificação intermacrossemiótica, isto é, de uma macrossemiótica - conjunto de todos os sistemas semióticos e seus discursos em operação numa comunidade sócio- linguístico- cultural - para outra macrossemiótica. Em se tratando de um sistema semiótico verbal, cabe ao tradutor restabelecer, re-criar na língua-meta o isomorfismo (no sentido hjelmsleviano) entre os planos da expressão e do conteúdo, estabelecidos na língua de partida. Este problema agrava-se, dramatiza-se, quando se trata de um texto poético: as razões parecem óbvias, face à pluri-isotopia desses textos.

As questões de natureza teórica suscitadas pelo problema da operação tradutora são, por óbvio, muito mais complexas e extensas do que as parcas observações aqui expostas. Contudo, elas têm como propósito exclusivo situar a perspectiva que vem orientando nossa ação prática no terreno da tradução, lembrando, ademais, que não consideramos possível efetuar um trabalho consciente de tradução sem uma postura teórica claramente definida diante dos procedimentos a serem adotados, sob pena de o texto traduzido tornar-se estéril, perdendo sentido(s) e qualidade. E isso inclui a prática do necessário e obrigatório cotejamento das soluções com traduções para outras línguas que o tradutor conheça.

Umberto Eco menciona, de modo explícito, a necessidade absoluta de o tradutor respeitar o sentido profundo do texto que transpõe para outra língua/cultura (ECO, 2003). Por outro lado, a noção de que traduzir é, em certa medida, transcriar no idioma de chegada para sempre respeitar (se e quando isso é factível) o texto original, torna-se mais aguda diante do texto poético. Foi com base nos conceitos mencionados que os textos traduzidos adiante também foram tratados.

As traduções de poetas poloneses que este tradutor não-nativo aventurou-se, de modo temerário, a realizar e, ainda por cima, a publicar, apareceram no volume intitulado Céu Vazio - 63 poetas eslavos (JOVANOVIĆ, 1996) ${ }^{1}$ em que foram traduzidos textos de poetas poloneses, sérvios, tchecos, eslovenos, croatas e macedônios. São textos de 63 poetas de línguas e nacionalidades eslavas, sendo 13 poloneses, 13 tchecos, 15 sérvios, 7 croatas, 4 eslovenos e 11 macedônios. Todos os poetas inseridos no livro são escritores do século XX; a única exceção foi Jan Kochanowski (1530-1584), que aparece no livro com três poemas traduzidos. Os demais autores poloneses foram Julian Tuwim, Czesław Miłosz, Miron Białoszewski, Tadeusz Różewicz, Tymoteusz Karpowicz,

\footnotetext{
${ }^{1}$ Traduções minhas do polonês: Tadeusz Różewicz - Minha Poesia, Medo; Tymoteusz Karpowicz - Sonho, Esboço para um poema de amor moderno.
} 
Wisława Szymborska, Zbigniew Herbert, Bogdan Czaykowski, Adam Zagajewski, Stanisław Barańczak, Ewa Lipska e Julian Kornhauser. Depois, a convite da editora Cosac Naify, traduzi alguns textos de Tadeusz Różewicz e Tymoteusz Karpowicz para o volume de Michael Hamburger (2007). ${ }^{2}$ Antologias sempre estão sujeitas a infindáveis questionamentos (justificáveis, por sinal): sempre dependem de fatores muito diversos, tais como a leitura idiossincrática do antologista, gosto e julgamentos pessoais, finalidade da coletânea, limitação de páginas imposta pela editora, etc., etc.

Segue exemplo de tradução-transcriação de texto do poeta Tadeusz Różewicz.

\section{Tadeusz Różewicz (1921-2014)}

\section{MOJA POEZJA}

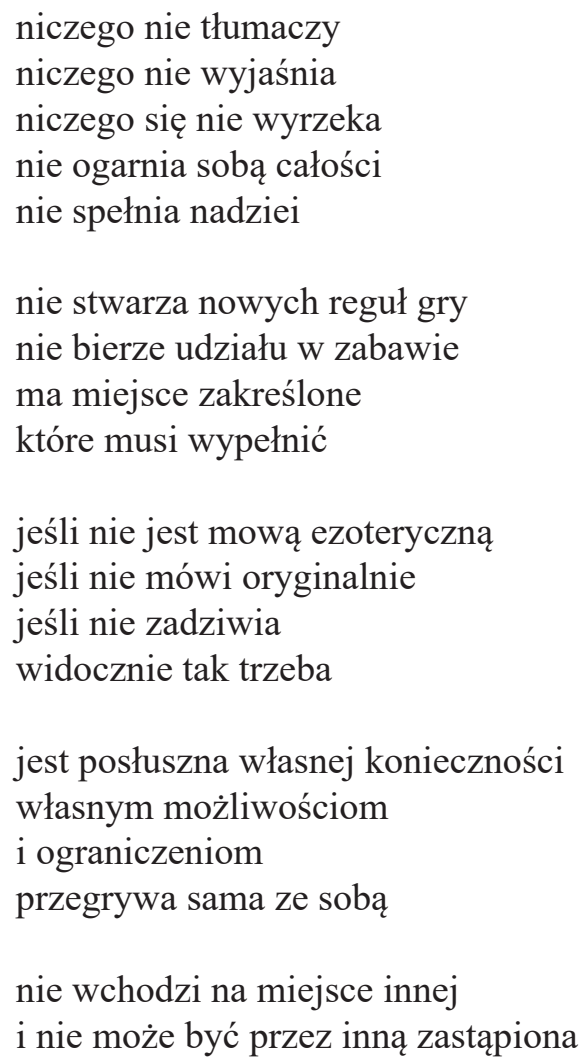

\footnotetext{
${ }^{2}$ Traduções minhas do polonês: Jan Kochanowski - Às Musas, A vida humana, Tília; Juliam Tuwim- Poema; Czesław Miłosz - História da Literatura Polonesa - Pequeno poema sobre o fim do mundo - Ars poética; Miron Białoszewski - Auto-retrato; Tymoteusz Karpowicz - Quem é o poeta, O retorno do poeta, Reabilitação post-mortem; Wisława Szymborska - Céu; Zbigniew Herbert - Informe da cidade sitiada; Bogdan Czaykowski - Revolta em versos; Adam Zagajewski - Derrota; Stanisław Barańczak - A longevidade dos executores; Ewa Lipska - Testamento, Estude a morte; Julian Kornhauser - Poesia.
} 
otwarta dla wszystkich

pozbawiona tajemnicy

ma wiele zadań

którym nigdy nie podoła

(1965)

\section{Minha poesia}

nada traduz

nada explica

nada expressa

não abarca totalidade alguma

não reifica esperança alguma

não cria regras novas do jogo

não participa dele

o lugar está delimitado

e ele deve completar

se não é fala esotérica

se não se expressa de modo original

se não deixa perplexo

assim deve então supostamente ser

obedece à própria necessidade

às próprias possibilidades

e limitações

perde para si mesmo

não substitui coisa alguma

não pode ser substituída por coisa alguma

aberta a todos

sem segredos

possui muitas tarefas

que jamais satisfaz

(1965) 


\section{REFERÊNCIAS:}

CAMPOS, Haroldo de. O Texto como Produção (Maiakóvski). In: CAMPOS, Haroldo de. A Operação do Texto. São Paulo: Perspectiva, 1976. p. 43-88.

CAMPOS, Haroldo de. Da Transcriação; Poética e Semiótica da Operação Tradutora. In: OLIVEIRA, Ana Claudia de; SANTAELLA, Lucia. Semiótica da Literatura. São Paulo: Educ, 1987.

ECO, Umberto. Dire quasi la stessa cosa. Esperienze di traduzione. Milano: Bompiani, 2003.

HAMBURGER, Michael. A verdade da poesia. São Paulo: Cosac Naify, 2007.

JOVANOVIĆ, Aleksandar (Org.). Céu Vazio - 63 poetas eslavos. Organização, estudo introdutório, notas biográficas e tradução de Aleksandar Jovanović. São Paulo: Hucitec, 1996.

ПОПОВА, Татијана. Верна неверност. Књижевниот превод како фактор на културата In: Меѓународна средба на књижевните преведувачи, 11., 1983, Тетово. Зборник на трудови од симпозиумот на ХІ Мегународна средба на книжевните преведувачи. Тетово: Советот на Меѓународна средба на књижевните преведувачи, 1983. p. 37-54. 